\title{
In vitro based multiplication of a superior Brazilian Cavendish banana clone
}

Shahnawaz Palijo ${ }^{1}$, Aneela Yasmin ${ }^{1}$, Amjad Ali Memon ${ }^{2 *}$, Anam Mehwish Khanzada ${ }^{3}$, Shoukat Ali Wassan ${ }^{2}$ and Rizwan Ahmed ${ }^{4}$

1. Department of Biotechnology, Faculty of Crop Production, Sindh Agriculture University, Tandojam-Pakistan

2. Department of Botany, Institute of Tropical Agriculture and Forestry, Hainan University-China

3. Plant Disease Research Institute, Tandojam, Sindh-Pakistan

4. Department of Agronomy, Faculty of Crop Production, Sindh Agriculture University, Tandojam-Pakistan

*Corresponding author's email: memon.hainu@gmail.com

Citation

Shahnawaz Palijo, Aneela Yasmin, Amjad Ali Memon, Anam Mehwish Khanzada, Shoukat Ali Wassan and Rizwan Ahmed. In vitro based multiplication of a superior Brazilian Cavendish banana clone. Pure and Applied Biology.Vol. 9, Issue 4, pp2497-2510. http://dx.doi.org/10.19045/bspab.2020.90266

\begin{tabular}{llll}
\hline \hline Received: 15/04/2020 & Revised: 01/07/2020 & Accepted: 09/07/2020 & Online First: 06/08/2020
\end{tabular}

\section{Abstract}

Propagation of Cavendish banana replica of Brazil under in vitro condition to influence the various growth regulators like Benzylaminopurine (BAP) and Indole-3-butyric acid (IBA) and their diverse concentrations for the production of mass of that replica. Among the tested concentration at the rate of BAP $\left(3.5 \mathrm{mgL}^{-1}\right)$ was found most favorable for maximum survival and regeneration of shoots $(95 \%)$ also observed highest shoot frequency $(100 \%)$ during $8^{\text {th }}$ week of in vitro culture. (1.7) shoots were recorded on $\left(0.5 \mathrm{mgL}^{-1}\right)$ of BAP and this number greater than before to (7.1) shoots per explants when $3.5 \mathrm{mgL}^{-1}$ of BAP used. LSD showed that the treatment $\left(3.5 \mathrm{mgL}^{-1}\right)$ of BAP had also greatest effect on shoot induction and stem length of plantlets and further amplify in BAP concentrations had no effect on shoot multiplication rather a reduction observed. While, T6 (IBA $\left.=1.5 \mathrm{mgL}^{-1}\right)$ showed a minimum number of days (17.1) for induction of roots respectively. The peak number of roots $(12.3)$, highest length of roots $(8.3 \mathrm{~cm})$ and $100 \%$ root multiplication after $6^{\text {th }}$ week again observed on T6 $\left(\mathrm{IBA}=1.5 \mathrm{mgL}^{-1}\right)$. In conclusion, IBA $(1.5$ $\mathrm{mgL}^{-1}$ ) T6 best treatment for plant vitality, which can show healthy small plants with $8.0 \mathrm{~cm}$ height or higher, with lush green broad leaves $4.0 \mathrm{~cm}$ or higher and developed roots. The healthy and complete plantlets were successfully transferred to pots after 1-week of lab hardening and later 4weeks in a climate box with high humidity. Control (garden soil) showed 35\%. While Soil+Coir (1:1) showed peak $90 \%$ survival rate of plantlets during the hardening process.

Keywords: Plant growth regulators; Concentrations; Brazilian cavendish banana clone; In vitro multiplication; Acclimatization

\section{Introduction}

Banana is (Musa spp.) an important food crop. It belongs to family Musaceae and widely cultivated in developing countries. It is thought that originated some hybridization event in Malaysia [1]. The reasons for its popularity are high year-round yield and acceptability to all communities. This crop cultivated in the tropical and sub-tropical areas of Asia pacific as Bangladesh, Philippines, Indonesia, Vietnam, Thailand and the south pacific islands, India etc. It also contributes in the economics of South China, Australia, Taiwan, Malaysia, and Sri Lanka. 
Pakistan also cultivates bananas but most of it is consumed in local markets [2].

It is immediate source of energy due to its high carbohydrate contented it also contains substantial amounts of phosphorus, calcium, potassium, vitamins $\mathrm{C}$ and more vitamins. Fascinatingly, it is used in tannin, latex and fiber production. In fruit crops it stands second after citrus and stands fourth in the list of staple foods of world following wheat, rice, and maize $[3,4]$. According to the nutritional analysis it contains $22 \%$ of carbohydrates, $0.84 \%$ fiber, $1.1 \%$ of protein, $0.2 \%$ of fat and $75.7 \%$ of water. It also has heating power against different cancers as renal, breast and colorectal $[5,6]$.

This valuable commercial crop is easy to cultivate in a wide range of environmental conditions. However, Pakistan is harvesting quite lower yields of banana crop as compared to other banana growing countries in the world due to non-professional practices and stresses of biotic \& abiotic on crop. Among biotic stress, viral diseases like; banana streak virus, black sigatoka, banana Xanthomonas wilt, fusarium wilt, and many others are an important factor for the production of banana mostly in Pakistan this crop is badly affected by banana bunchy top virus (BBTV) [7, 8]. During the early nineties (90s), in the banana fields of Sindh province, Pakistan, a mysterious disease spread which occupied more than $60 \%$ area due to which $90 \%$ production declined. In a while, the infectivity was recognized as Bunchy top disease of banana and produced by the bunchy top virus of banana. Virus vector is Pentalonia nigonervosa which contaminated plants and provide typical bunchy top emergence, which is owing to the failure of stand stiff and leaves flexibility. Due to the production weighty loss, farmers started cultivation of cotton and sugarcane instead of banana crop but they were not able to get high income, as compared to get from banana. So, to get the planting material which is disease free for re-cultivation of fields, all efforts were diverted, which were damaged by the BBTV of banana crop [9].

Due to triploid, it is propagated vegetative using suckers. Suckers are rhizomes that are cut from mature plants growing in field. Conventional breeding has its limitations to manipulate Musa species due to parthenocarpy and polyploidy [10]. Banana shoot-tip culture is the most suitable alternative for large scale banana production. Now this method is commercially adopted and 1.3 million plants are produced annually. Although plant tissue culture based clonal propagation is now a routine procedure, it involves high costs due to which laboratories with limited funds cannot be benefitted by this technology whereas, the traditional method of propagation cannot satisfy even the local demand of disease-free healthy banana material for planting. Traditionally, the multiplication rate of suckers is very slow; only 15 to 20 suckers per year are produced depending on clone, agro-climatic conditions and cultural methods. Moreover, Cavendish dwarf is grown on more than $90 \%$ area of Sindh, Pakistan province that is low yielding variety.

In world scenario, most of the countries that have increased their banana productivity adopted Cavendish clones that have superior yields such as Grand Naine, William Hybrid, some Brazilian and Chinese cultivars. Some new Cavendish clones are recently introduced in Sindh by Pakistan Agriculture Research Council (PARC) and few progressive farmers. Tissue culture techniques of plants can help to introduce \& disseminate new varieties within short time due to rapid mass production of plantlets. A banana cultivar can be very rapidly propagated by tissue culture (TC) and on average 10000 plants can be prepared using a single meristem during one year after optimizing conditions whereas 5-20 suckers only can be obtained from a mother plant in a 
year [11]. Due to this rapid multiplication few mother plants are required to get masses of offspring. Again, the maintenance of few plants is much cheaper and easy. Using shoot tip culture that is a vegetative method of propagation, true to type progeny is generated that takes after their mother phenotypically as well as genotypically with limited variation. Even this limited variation can be minimized by optimizing micropropagation methods and testing genetic variation time to time [12].

Many countries have adopted this technique as an alternative to conventional banana propagation like; India, Australia, France, and Africa countries. The explants used for banana In vitro propagation are shoot tips and male floral tissues [13, 14]. It's demonstrated that banana tissue culture in liquid media through somatic embryogenesis. It is found that banana multiplication rate depends on genotype $[15,16]$. Meristem culture is the most efficient individual for the production of material free from virus [17].Tissues cultured material is reported to produce about $39 \%$ higher yields than plant originate from suckers [18].

This study was carried out to optimize the multiplication media of a higher Cavendish Banana replica so that a sufficient amount of superior quality of material for planting could be generated on mass scale to introduce it commercially in the province of Sindh, Pakistan.

\section{Materials and methods}

This experiment was practiced in 2013 and 2014 at the laboratory of tissue culture. The plant material used in the experiment was superior Brazilian Cavendish banana replica gets in the form of suckers from the fields of experiment of Pathology sector, Agriculture Research Institution, Sindh, Pakistan. Suckers were used to optimize an in vitro based procedure for the mass production of this replica by micro propagation so that enough planting material could be generated in Sindh province for the farmers in near future.

\section{MS medium preparation}

MS media is the high salt-based combination of nutrients and commercially exists in powder form (Murashige and Skooge, 1962). For the preparation of 1L of MS solution, add $600 \mathrm{ml}$ of distilled water to $1 \mathrm{~L}$ of beaker and put it on the magnetic stirrer. Using the correct size of pipette, add all stock solutions (i.e. Macro and Micro nutrients, iron sources) to the beaker already comprising $600 \mathrm{ml}$ of filtered water. After that, each component was permitted to melt and the growth hormones were added in the media in accordance with applications. Solution was bringing to the final volume of thousand milliliters through means of graduated cylinder and by the addition of more distilled water. $\mathrm{pH}$ was maintained to 5.8 by the addition of $1 \mathrm{M} \mathrm{HCl} / \mathrm{NaOH}$ drops while stirring. Put the agar in the prepared medium and leave it for boiling so that the agar could be dissolve in it. After that, put the medium in labeled empty bottles for culturing and autoclaved for 35 minutes at $121^{\circ} \mathrm{C}$. After boiling keep the medium overnight at $37^{\circ} \mathrm{C}$ for cooling and check the sterilization quality. On the next day, media was ready to use for culturing of explants under laminar flow hood.

Note: Stock solutions of various quantity were prepared individually for Micro, macro nutrients, Vitamins $(50 \mathrm{x}, 5 \mathrm{x}, 50 \mathrm{x}$ respectively), and iron source (10x) through dissolve suitable quantity of particular salts in filtered water and kept at $4^{\circ} \mathrm{C}$.

\section{Preparations to initiate plant tissue culture}

Earlier than the explants treatments, laminar air flow was turned on \& exchanged by use of hundred percent spirits. Before the start of work, blower unit of laminar air flow and ultra violet light was turned on for minimum thirty minutes. All equipment like; scissors, scalpels, sterilized plastic, knives, forceps, medium bottles, spirit lamp, glass plates, 
Petri dishes, ring rubbers etc. were autoclaved and placed in laminar air flow cabinet. Laminar air flows have High Efficiency Particulate Air (HEPA) filters that clean the air \& confirmed that air flow above the table is totally sterilized. As there is permanent air-flow throughout immunization cabinet so it is basically not possible that dirt could overtake from outside.

\section{Explants preparations}

Vigorous suckers of banana, 1-2 feet in length, were taken from the experimental area. Suckers were then cleaned under tap running water to get rid of mud and further unnecessary materials. Leaves were detached from pseudo stem except the juvenile leaves around the tip of shoot and ex-plant becomes $2 \times 2 \times 2 \mathrm{~cm}^{3}$ enclosing the apex of shoot. Tips of shoot with meristem were acknowledged as ex-plant. For the sterilization of surface, at first these explants were dipped in $20 \%$ of house hold bleach with 2 to 3 drops of tween20 for twenty min. Then rinsed two to three times in sterilized distill water and explants were cut into dirt-free laminar air flow and cleaned with $70 \%$ of alcohol for few sec. Uncontaminated explants were immunized on Murashige and Skooge (MS) media holding different Benzylaminopurine (BAP) applications $(0.0,0.5,1.0,1.5,2.0,2.5,3.0$, $3.5,4.0,4.5,5.0$ milligram/L) or Indole-3butyric acid (IBA) $(0.0,0.25,0.5,0.75,1.0$, T5 1.25, 1.5, 1.75, 2.0 milligram/L) and incubated at $23 \pm 2^{\circ} \mathrm{C}$ for twelve hours of photoperiod.

Initiation of culture and multiplication of shoot was optimized by 6Benzylaminopurine. This phase was initiated with the tips of shoot as explants on the MS solid medium carrying agar or MS liquid media among cotton strand and in addition of various hormones applications as discussed before for ten weeks. Shoot formed from the phase of multiplication were cultivated separately on liquid MS medium comprising different Indole-3-butyric acid
(IBA) applications and incubated for eight weeks at $23 \pm 2$ degree Celsius. Separate rooted plantlets, were used under in vivo circumstances by means of various mixtures of pots and uncontaminated soil as control treatment, sand + coir (2:1), sand: coir $(1: 1)$ $\&$ sand + soil + cow dung $(1+1+1)$ for four to five weeks. Plantlets that were survived then shifted to the net house for more flourishing. Different parameters were studied throughout the experiment i.e. frequency of survival (\%), proliferation frequency of shoot (\%), shoot numbers per explants, length of stem $(\mathrm{cm})$, days taken to initiation of root, shoot/root numbers, root and shoot length $(\mathrm{cm})$, Multiplication rate of root $(\%)$, vigour of plant, rate of survival during hardening (\%). Thus, the data obtained were then used to analyze by Statistix 8.1.

\section{Results}

This experiment was conducted to obtain a procedure for micropropagation of superior Brazilian Cavendish banana clone that can replace Basrai cultivar of banana in Sindh, Pakistan. Various parameters were studied under in vitro condition to optimize the mass production of that clone.

\section{Frequency of survival (\%)}

Survival rate $(\%)$ of banana shoot tips under in vitro culture was practiced on ten different Benzylaminopurine (BAP) applications ranging from 0.5 to 5.0 milligram per liter with equal intervals of $0.5 \mathrm{mgL}^{-1}$ and a negative control that was the simple MS basal medium with no plant growth regulator or BAP. Shoot tips were cultured in sterile conditions and data was collected following 28 days of in vitro shoot tips growth with single sub-culture following fifteen days. This experiment was repeated two times with 20 explants in each replication. To obtain the frequency of survival of shoot tips, total number survived were divided to the total number of shoot tips cultured $\& \%$ age was noted (Fig 1). 
The depicted figure indicates that the BAP at the rate of 3.5 milligram per liter revealed the highest survival and regeneration of shoot tips $(95 \%)$ on average basis. Although the application of BAP lower than 3.5 milligram per liter indicates the low survival and regeneration rate of explants. The second maximum frequency of survival $(80.0 \%)$ and regeneration was observed on $\mathrm{BAP}$ at the rate of 3.0 milligram per liter. The frequency of survival on negative control is $(20 \%)$ that suggests the presence of indigenous growth regulators that helped the explants to grow even in a hormone free nutrient media. Hormones high applications in the media can encourage the growth of callus that involves the genetic inconsistency in cultures. In this case, such variation is not advantageous so that the optimal BAP application for the true to type plantlets mass production is 3.5 milligram per liter in MS basal medium.

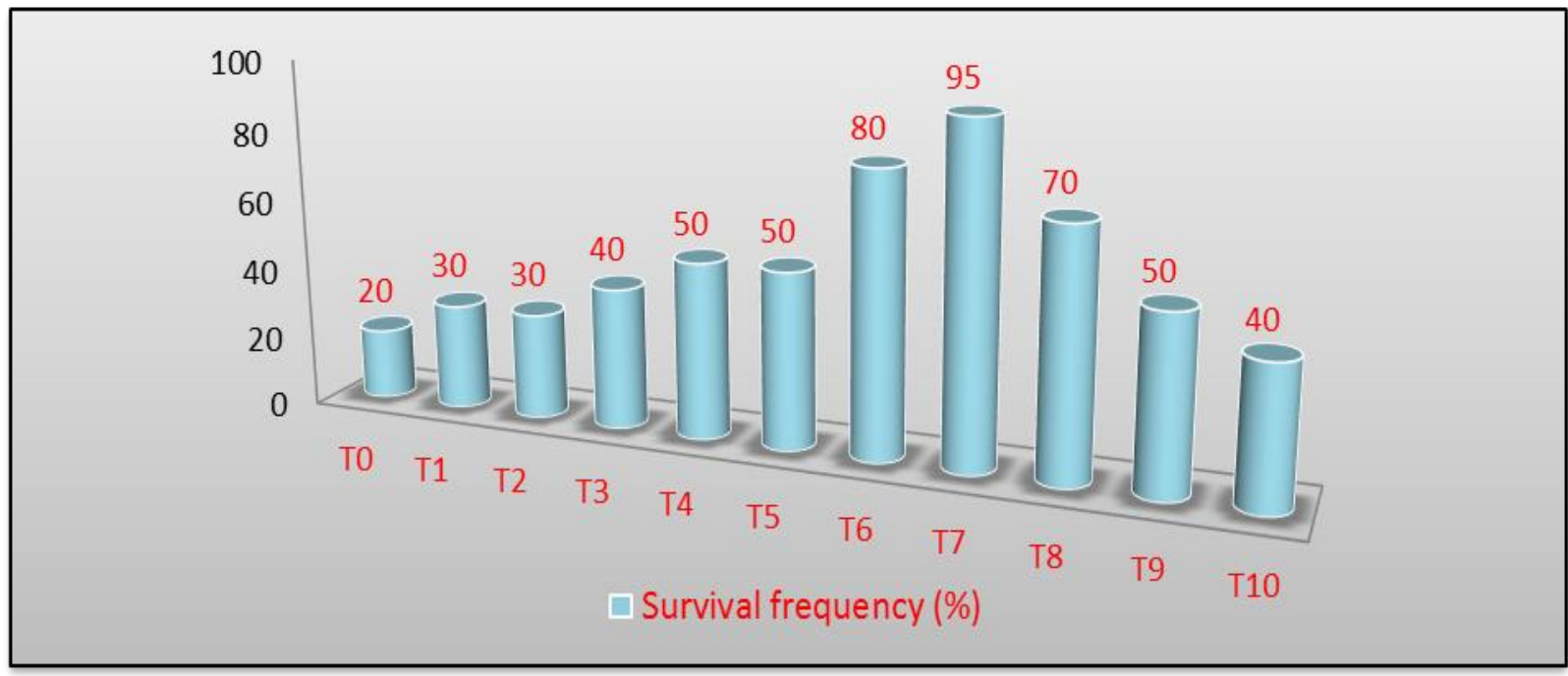

Treatments: T0=MS basal media without BAP, T1= MS media $+0.5 \mathrm{mgL}^{-1} \mathrm{BAP}, \mathrm{T} 2=\mathrm{MS}$ media+ $1.0 \mathrm{mgL}^{-1} \mathrm{BAP}$, T3= MS media+ $1.5 \mathrm{mgL}^{-1} \mathrm{BAP}$, T4= MS media+2.0 $\mathrm{mgL}^{-1} \mathrm{BAP}$, T5= MS media $2.5 \mathrm{mgL}^{-1} \mathrm{BAP}$, T6= MS media+ $3.0 \mathrm{mgL}^{-1}$ BAP,T7= MS media+ $3.5 \mathrm{mgL}^{-1} \mathrm{BAP}, \mathrm{T} 8=\mathrm{MS}$ media $+4.0 \mathrm{mgL}^{-1} \mathrm{BAP}$, T9=MS media $+4.5 \mathrm{mgL}^{-1} \mathrm{BAP}$, $\mathrm{T} 10=\mathrm{MS}$ media+ $5.0 \mathrm{mgL}^{-1} \mathrm{BAP}$.

\section{Figure 1. Survival frequency $(\%)$ of explants of Brazilian Cavendish banana clone under} different concentrations of BAP

\section{Shoot proliferation frequency $(\%)$}

Consequence of banana explants shoot proliferation rate under in vitro micro propagation is given in (Fig 2). Influence of ten BAP applications on banana shoot proliferation of banana was recorded on 5 evenly distinct intervals of time that were after 2, 4, 6, 8, \& 10 weeks respectively.

Maximum percentage of shoot proliferation frequency $(100 \%)$ was recorded during $8^{\text {th }}$ week of explants growth in MS medium supplemented with 3.5 milligram per liter of BAP. Negative control did not show any shoot proliferation until $8^{\text {th }}$ week while during the next two weeks only one explants showed shoot growth that resulted in a frequency of $(7 \%)$. This is motivating to inform that there was no proliferation of shoot in $1^{\text {st }} 7$ days of micro propagation in all considered applications, while there was an immediate shoot induction of shoot during second week of growth under in vitro condition. The proliferation of shoot during the first 2 weeks was emerged at BAP 0.5 milligram per liter $(8.3 \%)$ and improved correspondingly as the application of BAP improved up to 3.5 milligram per liter BAP $(58.3 \%)$ while proliferation percentage of 
shoot was steadily dropped at lofty application as compared to 3.5 milligram per liter of BAP.

During four to six weeks the rate of shoot proliferation improved as compared to two weeks of growth. During this study the explants were sub-cultured following each fifteen days on the same regime of media. During this interval of time (two to six weeks) again the maximum number of explants that resulted proliferation of shoot was observed at 3.5 milligram per liter of BAP i.e. (66.7) and (91.7\%) respectively.
Although control unsuccessful to proliferate any shoot $(0.00 \%)$. After seventy days of growth under in vitro, $100 \%$ explants resulted cultures shooting comprising 3.0 and 3.5 milligram per liter of BAP. In addition, BAP at the rate of 2.0, 2.5, and 4.0 milligram per liter also showed promising results after ten weeks and $(85,95$, and $93.3 \%)$ shoot tips showed new growth respectively. The results of this experiment showed that the BAP at the rate of 3.5 milligram per liter is the sharp drop and most proficient in proliferation of shoots and each explants $(100 \%)$ under in vitro.

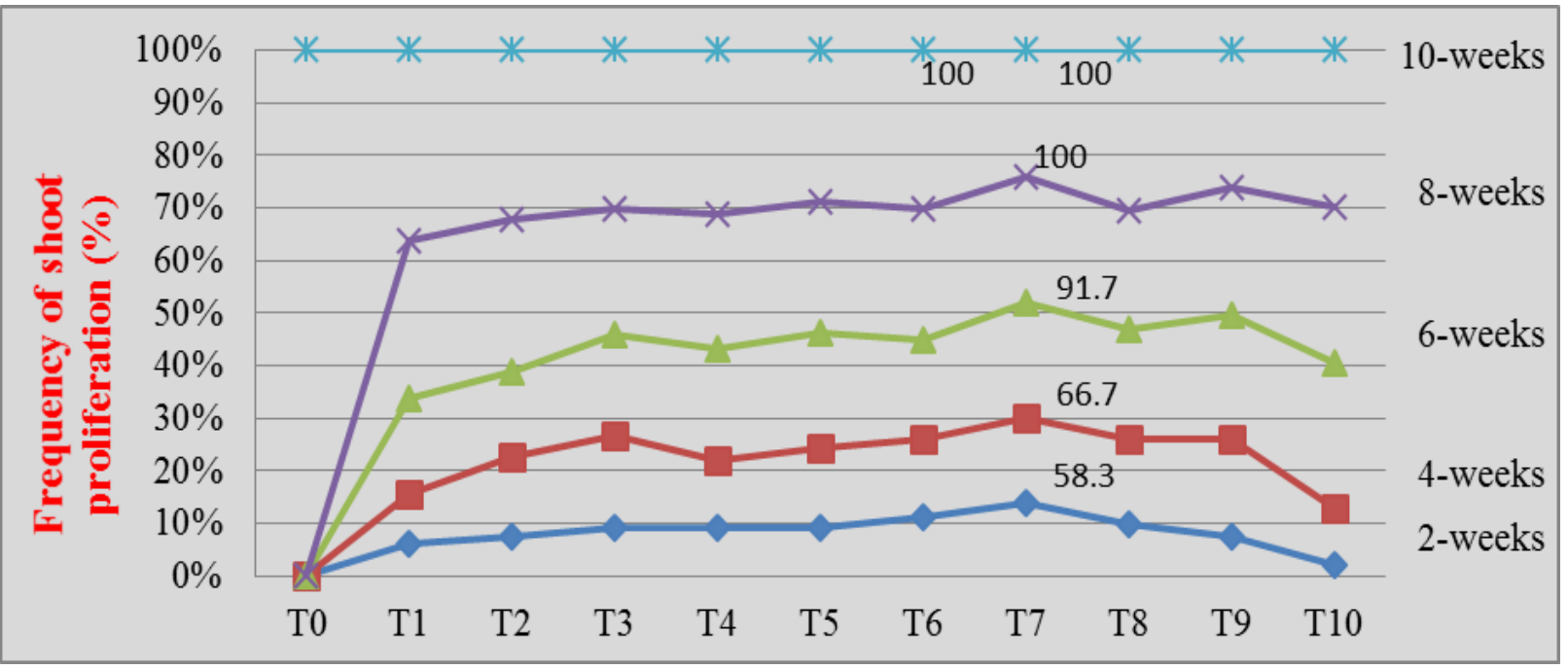

Treatments: $\mathrm{T} 0=\mathrm{MS}$ basal media without $\mathrm{BAP}, \mathrm{T} 1=\mathrm{MS}$ media $+0.5 \mathrm{mgL}^{-1} \mathrm{BAP}, \mathrm{T} 2=\mathrm{MS}$ media $+1.0 \mathrm{mgL}^{-1} \mathrm{BAP}$, $\mathrm{T} 3=\mathrm{MS}$ media $+1.5 \mathrm{mgL}^{-1} \mathrm{BAP}, \mathrm{T} 4=\mathrm{MS}$ media $+2.0 \mathrm{mgL}^{-1} \mathrm{BAP}, \mathrm{T} 5=\mathrm{MS}$ media $+2.5 \mathrm{mgL}^{-1} \mathrm{BAP}, \mathrm{T} 6=\mathrm{MS}$ media+ $3.0 \mathrm{mgL}^{-1} \mathrm{BAP}, \mathrm{T} 7=\mathrm{MS}$ media+ $3.5 \mathrm{mgL}^{-1} \mathrm{BAP}, \mathrm{T} 8=\mathrm{MS}$ media $+4.0 \mathrm{mgL}^{-1} \mathrm{BAP}, \mathrm{T} 9=\mathrm{MS}$ media $+4.5 \mathrm{mgL}^{-1} \mathrm{BAP}$, $\mathrm{T} 10=\mathrm{MS}$ media+ $5.0 \mathrm{mgL}^{-1} \mathrm{BAP}$.

Figure 2. Frequency of shoot proliferation of banana explants after various time intervals of micro propagation under different concentrations of BAP

\section{Shoot numbers per explants}

Shoot tips of Brazilian Cavendish banana cultured on basal media of MS completed with different BAP rates. Shoot numbers/explants observed after ten weeks of in vitro growth. Cultures were sub-cultured frequently after every 15 days to keep the complete supply of nutrients. Mean shoot numbers per each application were assessed by Least Standard Deviation (LSD) at $\mathrm{p}=$ 0.05 and various letters are added in the front of means showing significant differences among the tested means. (Table 1) indicates that highest shoot numbers recorded (7.1) when used BAP 3.5 milligram per liter. The influence of these applications was checked using ANOVA and a highly significant difference was found among the treatments. LSD showed that the application 3.5 milligram per liter of BAP has highest influence on shoot induction. BAP at rate of 3.0 milligram per liter revealed (5.4) shoot per explants on average. Nevertheless, the difference between (7.1) and (5.4) shoot was 
established insignificant at LSD $\mathrm{p}=0.05$. This is also the same application on which the highest rate of survival and proliferation of shoot (\%) was recorded. Moreover, negative control produced the poorest number of shoots (0.2). There was no shoot induction till the $8^{\text {th }}$ week and $10^{\text {th }}$ week of in vitro culture without growth regulator MS media.

\begin{tabular}{|c|c|c|}
\hline $\begin{array}{c}\text { Treatments } \\
\text { MS+BAP }\left(\mathbf{m g L}^{-\mathbf{1}}\right)\end{array}$ & Number of shoots per explants & Length of stem (cm) \\
\hline 0.0 & $0.2 \pm 0.2 \mathrm{e}$ & $3.7 \pm 0.5 \mathrm{f}$ \\
\hline 0.5 & $1.7 \pm 0.4 \mathrm{de}$ & $5.6 \pm 0.5 \mathrm{de}$ \\
\hline 1.0 & $2.6 \pm 0.6 \mathrm{~cd}$ & $5.9 \pm 0.6 \mathrm{~cd}$ \\
\hline 1.5 & $2.6 \pm 1.4 \mathrm{~cd}$ & $5.6 \pm 1.2 \mathrm{de}$ \\
\hline 2.0 & $3.2 \pm 0.9 \mathrm{~cd}$ & $6.0 \pm 0.8 \mathrm{~cd}$ \\
\hline 2.5 & $4.3 \pm 1.1 \mathrm{bc}$ & $7.0 \pm 1.7 \mathrm{bcd}$ \\
\hline 3.0 & $5.4 \pm 1.0 \mathrm{ab}$ & $8.3 \pm 0.9 \mathrm{~b}$ \\
\hline 3.5 & $7.1 \pm 1.7 \mathrm{a}$ & $10.1 \pm 0.9 \mathrm{a}$ \\
\hline 4.0 & $3.5 \pm 1.5 \mathrm{~cd}$ & $7.3 \pm 0.6 \mathrm{bc}$ \\
\hline 4.5 & $2.1 \pm 0.8 \mathrm{~d}$ & $5.5 \pm 0.7 \mathrm{de}$ \\
\hline 5.0 & $2.2 \pm 1.0 \mathrm{~d}$ & $4.2 \pm 1.1 \mathrm{ef}$ \\
\hline LSD & 1.77 & 1.56 \\
\hline S.E & 0.85 & 0.75 \\
\hline
\end{tabular}

Table 1. Number of shoots per explants and Length of stem $(\mathrm{cm})$ of banana at various concentrations of BAP

\section{Stem length $(\mathrm{cm})$}

The influence of BAP applications on banana stem length under in vitro was considered and the data is given in (Table 1). ANOVA of this data indicates highly significant influence of BAP applications on micro propagated shoot length. LSD at $\mathrm{p}=0.05$ revealed the presence of six different mean populations among these treatments.

Application of BAP at 3.5 milligram per liter was found considerably different showing the highest length of plantlets stem $(10.1 \mathrm{~cm})$ regenerated during ten weeks of in vitro growth, followed by BAP 3.0 milligram per liter. The second highest length of stem (8.3 $\mathrm{cm})$ was recorded growing in these cultures. Supplementary increase application of BAP had no influence on growth of stem rather stable reduce was recorded. Lowest length of stem $(3.7 \mathrm{~cm})$ was recorded in negative control that was insignificantly different from the treatment of BAP $\left(5.0 \mathrm{mgL}^{-1}\right)$ which showed $(4.2 \mathrm{~cm})$ longer stem in average. Thus, the result revealed that BAP $3.5 \mathrm{mgL}^{-1}$ application is best for the length of stem (10.1 $\mathrm{cm}$ ) of micro propagated plantlets in the basal media of MS.

\section{Days taken to initiate roots}

The influence of 08 various applications of Indole-3-butyric acid (IBA) was assessed for root induction under in vitro condition that generated banana shoot lets. In this observation, the number of days was observed to be in use by shoots to start roots at IBA various concentrations (Table 2). ANOVA revealed highly significant difference among the treatments and LSD $(p=0.05)$ revealed the presence of various mean populations.

The application $6(\mathrm{IBA}=1.5$ milligram per liter) for root induction showed least days that is (17.1) days followed by treatments 7 and 8 respectively. Treatment $7(\mathrm{IBA}=1.75$ milligram per liter) and treatment $8(\mathrm{IBA}=$ 2.0 milligram per liter) took (23.5) and (23.8) days to initiate roots; the difference between these two treatments was found insignificant at $\mathrm{p}=0.05$. The relationship among negative 
control and the other applications revealed that induction of root is not feasible without IBA during 42 days of culture under in vitro condition. As swift IBA was included to media it appeared its influence in the root induction shape.

Table 2. Days taken to initiate roots, Number of roots per shootlet, Length of roots per shootlet $(\mathrm{cm})$ of banana, at various concentrations of IBA supplemented in MS medium

\begin{tabular}{|c|c|c|c|}
\hline $\begin{array}{c}\text { Treatments } \\
\text { MS+IBA }\left(\mathbf{m g L}^{-1}\right)\end{array}$ & $\begin{array}{c}\text { Days taken to initiate } \\
\text { roots }\end{array}$ & $\begin{array}{c}\text { Number of roots per } \\
\text { shootlet }\end{array}$ & $\begin{array}{c}\text { Length of roots per } \\
\text { shootlet }(\mathbf{c m})\end{array}$ \\
\hline $\mathrm{T} 0=0.0$ & $0.0 \pm 0.0 \mathrm{f}$ & $0.3 \pm 0.2 \mathrm{c}$ & $0.2 \pm 0.2 \mathrm{~d}$ \\
\hline $\mathrm{T} 1=0.25$ & $38.7 \pm 1.5 \mathrm{a}$ & $7.1 \pm 1.6 \mathrm{~b}$ & $2.1 \pm 0.7 \mathrm{bc}$ \\
\hline $\mathrm{T} 2=0.50$ & $35.6 \pm 3.5 \mathrm{ab}$ & $7.4 \pm 0.7 \mathrm{~b}$ & $2.5 \pm 0.8 \mathrm{bc}$ \\
\hline $\mathrm{T} 3=0.75$ & $32.9 \pm 2.3 \mathrm{~b}$ & $8.2 \pm 1.2 \mathrm{~b}$ & $4.3 \pm 1.0 \mathrm{~b}$ \\
\hline $\mathrm{T} 4=1.0$ & $31.9 \pm 3.3 \mathrm{bc}$ & $8.2 \pm 2.3 \mathrm{~b}$ & $6.5 \pm 0.7 \mathrm{a}$ \\
\hline $\mathrm{T} 5=1.25$ & $28.6 \pm 1.7 \mathrm{c}$ & $8.2 \pm 0.9 \mathrm{~b}$ & $7.3 \pm 1.1 \mathrm{a}$ \\
\hline $\mathrm{T} 6=1.50$ & $17.1 \pm 1.6 \mathrm{e}$ & $12.3 \pm 2.5 \mathrm{a}$ & $8.3 \pm 1.2 \mathrm{a}$ \\
\hline $\mathrm{T} 7=1.75$ & $23.5 \pm 1.9 \mathrm{~d}$ & $8.5 \pm 1.5 \mathrm{~b}$ & $7.1 \pm 1.6 \mathrm{a}$ \\
\hline $\mathrm{T} 8=2.0$ & $23.8 \pm 2.0 \mathrm{~d}$ & $8.3 \pm 1.7 \mathrm{~b}$ & $7.4 \pm 2.2 \mathrm{a}$ \\
\hline LSD & 3.79 & 2.67 & 2.03 \\
\hline S.E & 1.80 & 1.27 & 0.96 \\
\hline
\end{tabular}

Table 3. Multiplication rate $(\%)$ of roots per shootlet of banana after various time intervals of micro propagation under different concentration of IBA

\begin{tabular}{|c|c|c|c|c|}
\hline \multirow{2}{*}{$\begin{array}{c}\text { Treatments } \\
\text { MS+IBA (mgL- } \\
\text { 1) }\end{array}$} & \multicolumn{4}{|c|}{$\begin{array}{c}\text { Roots multiplication rate }(\%)=\text { No. of shootlets with roots } \\
\text { Total No. of shootlets }\end{array}$} \\
\hline & 2 weeks & 4 weeks & 6 weeks & 8 weeks \\
\hline $\mathrm{T} 0=0.0$ & 0.0 & 0.0 & 0.0 & 13.3 \\
\hline $\mathrm{T} 1=0.25$ & 23.3 & 36.7 & 46.7 & 63.3 \\
\hline $\mathrm{T} 2=0.50$ & 30.0 & 50.0 & 56.7 & 70.0 \\
\hline $\mathrm{T} 3=0.75$ & 26.7 & 40.0 & 76.7 & 90.0 \\
\hline $\mathrm{T} 4=1.0$ & 50.0 & 76.7 & 86.7 & 100.0 \\
\hline $\mathrm{T} 5=1.25$ & 53.3 & 80.0 & 93.3 & 100.0 \\
\hline $\mathrm{T} 6=1.50$ & 60.0 & 86.7 & 100.0 & 100.0 \\
\hline $\mathrm{T} 7=1.75$ & 56.7 & 90.0 & 100.0 & 100.0 \\
\hline $\mathrm{T} 8=2.0$ & 53.3 & 90.0 & 100.0 & 100.0 \\
\hline
\end{tabular}

Note: The total number of shootlets in each replication for this parameter was 10 and three replications were carried out to get the presented data.

\section{Number of roots/shoot}

Root numbers per shoot let was observed after eight weeks of growth under In vitro to assess the influence of various IBA applications. IBA used to persuade rooting in glass cultures because it is an auxin. Replication means are analyzed through ANOVA, mean three replications number of roots (Table 2) presented, which indicates highly significant influence of IBA on root numbers. Means are further analyzed by LSD $(p=0.05)$ that revealed the presence of three mean populations.

The maximum root numbers (12.3) were noted in T6 (IBA $=1.5$ milligram per liter). Applications 1, 2, 3, 4, 5, 7 and 8 signify one mean population and representing nonsignificant differences between the mean roots numbers induced on particular applications. It may be noted from the 
observations that $\mathrm{T} 6(\mathrm{IBA}=1.5$ milligram per liter) represents various single average populations that have a significant impact on the number of roots/shoots. It was noticed that the negative control did not show any induction of root up to six weeks but revealed following 8-weeks of growth under in vitro without plant hormone and showed minimum root numbers per shoot (0.3). Thus, IBA at the rate of 1.5 milligram per liter can be measured the best application which established highest root numbers (12.3 roots per shoot) in difference to other high or low IBA applications in full power of MS basal media.

\section{Length of root/shoot $(\mathrm{cm})$}

Root length per shoot was studied to check the influence of various applications of IBA. In this observation, $8-10 \mathrm{~cm}$ lengthy in vitro generated banana shoots propagated on MS media comprising various IBA applications. Length root /shoot mean data given (Table 2). Analysis of difference showed extremely significant differences among treatments that indicate a strong effect of hormone on the length of root. On the basis of LSD @ p=0.05 T4 to T8 were found significantly different from each other.

Treatment T6 (IBA $=1.5$ milligram per liter) showed the maximum root length $(8.3 \mathrm{~cm})$ followed by $\mathrm{T} 8$ (IBA $=2.0 \mathrm{mgL}^{-1}$; root length $=7.4 \mathrm{~cm})$. However, LSD revealed that these statistics are not considerably different from others. Thus; several applications can be used to obtain similar root length per shoot lets under in vitro. Negative control showed minimum length of roots due to absence of growth regulator. Root was induced on shoots following 42 days of in vitro condition with regular sub-culture following every fifteen days.

\section{Roots multiplication rate $(\%)$}

Multiplication frequency of root was checked at various time intervals to assess the influence of various applications of IBA. For these reasons, data was taken during eight weeks of banana shoots lets in vitro culture of IBA. The intervals of time were 2, 4, 6 and 8 weeks with 8 various IBA applications were assessed for their influence on the root multiplication rate of banana shoot lets. Shoots numbers with roots was observed on various intervals of time (Table 3 ).

It was observed that there was no root induced when IBA was not added to media in T0 (negative control) till the $6^{\text {th }}$ week of in vitro culture. Later, during last two weeks $\left(7^{\text {th }}\right.$ and $8^{\text {th }}$ week) of observations $(13.3 \%)$ lowest rate of root multiplication was observed by T0 (negative control). T1 to T8 various IBA amounts were included in MS media and the rate of root multiplication was enhanced increasingly. This is clear from the data that IBA applications and the induction of root are directly proportional and as the rate of IBA was improved from 0.25 milligram per liter to 2.0 milligram per liter and the multiplication rate of root was also improved. Observation during the $6^{\text {th }}$ week, hundred percent multiplication of root was observed in treatments $\mathrm{T} 6(\mathrm{IBA}=1.50$ milligram per liter), $\mathrm{T} 7$ (IBA= 1.75 milligram per liter) and $\mathrm{T} 8(\mathrm{IBA}=2.0$ milligram per liter) this figure was improved during $8^{\text {th }}$ week and T4 (IBA= 1.0 milligram per liter) plus $\mathrm{T} 5(\mathrm{IBA}=1.25$ milligram per liter) also reported $100 \%$ induction of root. Similarly, T1 - T3 also reported enhancement in the multiplication of root with augment in time. Though, T6 - T8 are best IBA applications that may be used in the tissue culture of banana for root induction.

\section{Plant vigour}

The parameters noted in plant vigor were leaves color and rated on a scale i.e. $0=$ yellow, 1= yellowish green, 2= greenish yellow, $3=$ lush green, leaves width $(0=1.0$ $\mathrm{cm}, 1=2.0 \mathrm{~cm}, 2=3.0 \mathrm{~cm}, 3=4.0 \mathrm{~cm})$, plantlet height $(0=3.0 \mathrm{~cm}, 1=4-5.0 \mathrm{~cm}, 2=6$ $7.0 \mathrm{~cm}, 3=8.0 \mathrm{~cm}$ and above) and root system $(0=$ just root induction, $1=$ few roots, $2=$ few 
roots with secondary roots, $3=$ many lengthy roots with secondary roots network).

Data showed (Table 4) that T6 is the best application of IBA (1.5 milligram per liter) which showed healthy plantlets of height 8.0 $\mathrm{cm}$ and above with lush green wide $(4.0 \mathrm{~cm}$ or high) leaves and highly developed system for rooting. Other applications also had good influence on the vigor of plant for plantlets acquired broad leaves that will assist to carry out vigorous photosynthesis and tackle with field situations.

Table 4. Plant vigour of micropropagated banana plantlets under different concentrations of IBA

\begin{tabular}{|c|c|c|c|c|c|}
\hline \multirow{2}{*}{$\begin{array}{c}\text { Treatments } \\
\text { MS+IBA (mgL- } \\
\text { 1) }\end{array}$} & \multicolumn{4}{|c|}{ Plant vigour } & \multirow{2}{*}{ Total score } \\
\hline & $\begin{array}{c}\text { Green } \\
\text { Leaves }\end{array}$ & Leaves width & $\begin{array}{c}\text { Plantlet } \\
\text { height }\end{array}$ & Root system & \\
\hline $\mathrm{T} 0=0.0$ & 1 & 0 & 0 & 0 & 1 \\
\hline $\mathrm{T} 1=0.25$ & 2 & 1 & 1 & 1 & 5 \\
\hline $\mathrm{T} 2=0.50$ & 2 & 2 & 1 & 1 & 6 \\
\hline $\mathrm{T} 3=0.75$ & 2 & 2 & 2 & 2 & 8 \\
\hline $\mathrm{T} 4=1.0$ & 3 & 2 & 3 & 2 & 10 \\
\hline $\mathrm{T} 5=1.25$ & 3 & 3 & 3 & 2 & 11 \\
\hline $\mathrm{T} 6=1.50$ & 3 & 3 & 3 & 3 & 12 \\
\hline $\mathrm{T} 7=1.75$ & 2 & 1 & 3 & 3 & 9 \\
\hline $\mathrm{T} 8=2.0$ & 2 & 1 & 1 & 2 & 6 \\
\hline
\end{tabular}

Note: The plant vigour of 10 complete plantlets ready for hardening was visually scored on a scale of 0 to 3 . Where 0 shows no results, 1 is for fair, 2 is for good and 3 represents excellent growth in the perspective described at the top of columns.

\section{Survival rate during hardening $(\%)$}

After victorious banana in vitro generation plantlets were moved in pots to maintain usual field situations. During the initial week of acclimatization, the plantlets bottles were kept open for a little time in the growth room. Such well rooted hardened plantlets were removed from culture vessels without root damage. Agar was cleaned carefully from roots in hot water. After that, these plantlets were treated with fungicide for 30 seconds and shifted to little pots filled with four different pot mixtures to enhance the rate of survival of in vitro generated plantlets. These mixtures contain simple soil from garden as a control, soil: sand: cow dung (1:1:1), soil: coir (2:1) and soil: coir (1:1). The results on survival frequency $(\%)$ during the hardening are given in (Fig. 3).

Soil + Coir mixture was used in two different ratios that were $(2: 1)$ and (1:1), these mixtures performed better than two former pot mixes and survival rate increased to $(80 \%)$ and $(90 \%)$ respectively. Control (garden soil) showed 35\% survival rate of plantlets during hardening and most of the plantlets became yellow within first few days. Cultured of plantlets in these pot mixtures were kept beneath climate box with high humidity. After 4-weeks of proper care plants started new growth and planted in the field conditions. 


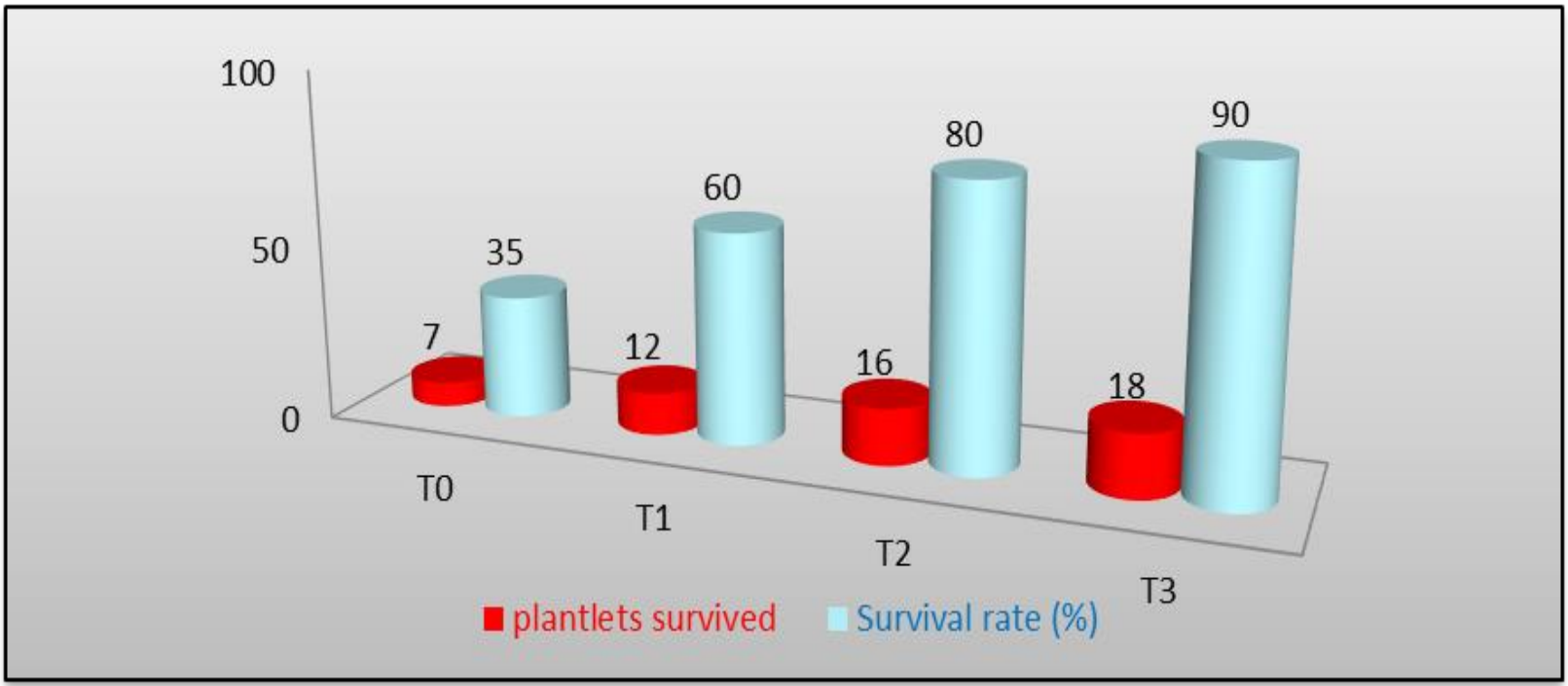

The total number of plantlets used to evaluate the effect of each pot mixture on plantlet survival was 20. First bar (darker) in graph shows the actual number of survived plantlets whereas second bar (lighter) shows the survival rate in percentage. Treatments: T0=Soil (control), T1=Sand+Soil+Cowdung (1:1:1), T2=Sand+Coir (2:1), T3=Soil+Coir $(1: 1)$.

\section{Figure 3. Survival rate (\%) of plantlets during hardening}

\section{Discussion}

Propagation under in vitro is significant technique for the banana mass production for planting that is free from virus of the available varieties and may assist in the quick induction and new varieties sharing via quick reproduction. Thus, the objective of this experiment was to optimize the procedure for mass reproduction of new variety under in vitro therefore superior Cavendish replica of Brazil, acquired from Research society for Agriculture, Tandojam. Thus, this replica mass reproduction may be accomplished to supply enough substances for planting to the farmers belongs to Sindh, Pakistan for cultivation of this replica on commercial scale to enhance yield and decrease losses owing to diseases.

As discussed before that plant TC techniques might also facilitate in quick induction and distribution of novel varieties, conventionally bananas are propagated through suckers. Due to increase in viral disease, the superiority of this planting substance is problematic [7]. Additionally, just seven to ten suckers are produced annually per plant and that is insufficient to complete the plantlets order for one and more acre. According to this condition, techniques of micro propagation are feasible to obtain masses of planting stuff in one year. [7] Reported that one tissue of meristematic may produce ten thousand plantlets within a year after seven subcultures. This is due to banana shoot short multiplication cycle (four weeks) \& every cycle consequences in the increase of plantlet number all over the year whatever of period [12].

Hence, in this experiment, we accomplished sterilization by means of house hold and obtained extremely hygienic cultures. Uncontaminated explants were cultivated on MS medium in addition to by various Benzylaminopurine (BAP) quantities and rate of survival was assessed. Results showed that explants survival rate of improves as the BAP quantity is improved until best quantity. In this experiment, highest frequency of survival was obtained on BAP at the application rate of 3.5 milligram per liter that was 95\%. Promote enhance in BAP decreased the frequency of survival 
gradually. Similar actions were stated by [19]. This is essential inform that in the first month culture, shoot tip outer leaf turned into green with also improvement in size and plenty of blackening in medium and it was all due to phenolic compounds emission.

In vitro experiments on the proliferation of shoot $(\%)$ reported that BAP applications and proliferation of shoot have a directly proportional relative until optimal application is attained afterward an inversely proportional performance was recorded. BAP at rate of 3.5 milligram per liter was reported again optimal and 100 percent proliferation of shoot was obtained throughout eight weeks of culture under in vitro. [20] Moreover reported related BAP results on Ndiziwemiti and Kibuzi under in vitro propagation. They observed the increase in development with the enhancement of BAP up to 3.6 milligram per liter and an unexpected death beyond that BAP application.

Explants multiplied on various BAP rates for ten weeks and the shoot numbers were noted. Shoot numbers also improved as the BAP application increased in MS medium. Maximum shoot numbers observed was 7.1 on BAP 3.5 milligram per liter that is important statistically. Now other experiment, [3] checked the BAP + kinetin mixture on the shoot multiplication also established the bad influence of high cytokinins applications. They observed the decrease in shoot numbers from 14.12 - 5.05 of Nendran banana variety, when the concentrations of BAP increased to 20.0 milligram per liter. [2] Practical the different Benzylaminopurine (BAP) and Naphthalene acetic acid (NAA) concentrations influence on the banana cv. Bari micro propagation. He observed that BAP lying on the rate of 7.5 milligram per liter with NAA 0.5 milligram per liter like the best possible application to produce the highest stem $(3.38 \mathrm{~cm})$ in thirty days of post culture. In dissimilarity, we observed that BAP at 3.5 milligram of optimal to encourage the highest shoots/stem. This variation could be owing to unusual genotypes and growth regulators composition. [21] stated the use of BAP with Indole acetic acid (IAA) as the mainly efficient composition for multiplication of shoots in a number of banana cultivars. In difference, we determined the single growth regulator usage for the multiplication of shoot.

During this experiment, only BAP included in MS media while; Al-amin and colleagues have applied different combinations of BAP and NAA. They observed 6.25 shoots per explants, long shoots of height $3.38 \mathrm{~cm}$ and highest leaves per plantlet (7.00) in thirty days and at the rate of BAP (7.5 milligram per liter) and NAA (0.5 milligram per liter) respectively. The data we expressed in present experiment taken during ten weeks of growth under in vitro and BAP at the rate of 3.5 milligram per liter was establish optimal that exposed hundred percent proliferation of shoot, 95 percent survival frequency, 7.1 percent shoots per explants and $10.1 \mathrm{~cm}$ of long stem. Such big variation is mainly owing to genotype, growth regulator compositions, culture conditions and chemicals. [22] Famous various multiplication rates even between explants taken from the same genotype and described these various multiplication rates due to physiological reaction of various rhizomes.

After the proliferation of shoot, due to mixing of auxins in the nutrient media rooting is induced. There are information's viewing the usage of MS media half strength for the induction of root [2]. In this experiment, IBA full potency was used in MS basal media to begin rooting. We experienced various IBA applications i.e. $0.25,0.5,0.75,1.0,1.25,1.5$, $1.75,2.0$ milligram per liter and found that IBA at the rate of 1.5 milligram per liter as best. Parameters deliberated to get optimal applications where days taken to start roots 
(17.1 days), root numbers (12.3), root length $(8.3 \mathrm{~cm})$, multiplication frequency of root (100\% in six weeks) and vigor of plant. [2] Declared that MS media half potency with IBA at the rate of $0,0.5,1.0$ and 1.50 milligram per liter and IAA $(0,0.5$ and 1.0 milligram per liter) for the induction of root and gave the highest number (6.50) and root length $(5.88 \mathrm{~cm})$ on IAA at the rate of 0.5 milligram per liter in combination with IBA at the rate of 0.5 milligram per liter. In agreement to this experiment [23] applied only one growth regulator that is IBA and found 8.28 roots per plantlet at 0.5 milligram per liter of IBA.

Whole in vitro generated healthy plantlets obtained from shoot tips were shifted following 1 week of hardening in laboratory to 4 various pot mixtures that comprises control (simple garden soil), soil: sand: cow dung (1:1:1), soil: coir (2:1) and soil: coir (1:1). $90 \%$ percent frequency of survival was distinguished in soil, coir (1:1) mixture and plantlets took four extra weeks to verify the fresh growth. Likewise, [2] as well set the plantlets generated under in vitro condition at temperature of 28 to $30^{\circ} \mathrm{C}$ for seven days. In differentiation, he organized plantlets generated under in vitro in the pot containing mixtures of ground soil with cow dung (1:1).

\section{Conclusion}

In current experiment, Brazilian banana cultivar shoot tip culture was optimized according to which tip of the shoot extract from the field grown banana sword suckers of height 1- 2 feet can be cultured on MS media comprising of BAP (3.5 milligram per liter) to get the maximum and healthiest shoot multiplication with wide leaves and good length. Regenerated shoots then can be rooted on IBA (1.5 milligram per liter) and sifted to pots having a combination of soil + coir (1:1) after 1-weeks of weaning in lab and four weeks in climate box under high humidity. Thus, this optimized protocol could be used for the mass production of
Brazilian banana cultivar to dissimilate its planting material among the farmers of Sindh province for replacing banana cv. Basrai.

\section{Authors' contributions}

Conceived and designed the experiments: $S$ Palijo, A Yasmin \& AA Memon, Performed the experiments: S Palijo \& A Yamin, Analyzed the data: S Palijo, A Yasmin \& AA Memon, Contributed reagents/ materials/ analysis tools: S Palijo, AM Khanzada, SA Wassan \& R Ahmed, Wrote the paper: AA Memon.

\section{References}

1. Novak FJ (1992). Musa (Banana and Plantains). In: Hammerschlag, FA and Litz, RE (eds), Biotechnology of perennial fruit crops. CAB Int University Press, Cambridge, UK. pp. 449-488.

2. AL-Amin MD, Karim MR, Amin MR, Rahman S \& Mamun ANM (2009). In vitro micropropagation of banana (Musa spp.). Bang J Agril Res 34(4): 645-659.

3. Madhulatha P, Kirubakaran SI \& Sakthivel N (2004). Effect of carbon sources and auxins on in vitro propagation of banana. Biologia plantarum 50(4): 782-784.

4. FAO (2012). FAOSTAT. Available at [http://faostat.fao.org]

5. Zhang CX (2009). Greater vegetable and fruit intake is associated with a lower risk of breast cancer among Chinese women. Int J Cancer 125(1): 181-188.

6. Rashidkhani B, Lindblad P \& Wolk A (2005). Fruits, vegetables and risk of renal cell carcinoma. Int J Cancer 113(3): 451-455.

7. Lepoivre $\mathrm{P}$ (2000). Banana in vitro regeneration: Laboratory of plant pathology, University of Gembloux, Belgium. pp. 22.

8. Tripathi L, Tripathi NJ \& Tushemereirwe WK (2008). Rapid and efficient production of transgenic East African Highland Banana (Musa spp.) using 
intercalary meristematic tissues. Afr $J$ of Biotec 7(10): 1438-144.

9. Memon AA, Raza A, Palijo S, Wenqian X \& Xueyan X (2019). Effect of carbon sources and their various concentrations for optimize in in vitro micro propagation of banana (Musa spp.) Basrai.http://dx.doi.org/10.22161/ijeab.4 434.

10. Capdeville G, Souza MT, Szinay D, Wijnker E \& DeJong H (2009). The potential of high-resolution BAC-FISH in banana breeding. Euphytica 166: 431443.

11. Mantell SH, Mathews JA \& McKee RA (1985). Principles of Biotechnology. Blackwell Scientific Pub, Oxford, UK. pp. 269.

12. Razdan MK (1993). An introduction to plant tissue culture. Oxford and IBH publishing Co. Pvt. Ltd. New Dehli. 342.

13. Escalant JV, Tession C \& Cote F (1994). Amplified somatic embryogenesis from male flowers of triploid banana and plantain cultivars (Musa spp.) In vitro Cell Dev Biol 30: 181-186.

14. Cronauer SS \& Krikorian AD (1984). Multiplication of Musa from excised stem tips. Ann Bot 53(3): 321-328.

15. Novak FJ (1992). Musa (Banana and Plantains). In: Hammerschlag, FA \& Litz, R. E. (eds), Biotechnology of perennial fruit crops. CAB Int University Press, Cambridge, UK. pp. 449-488.

16. Muhammad A, Hussain I, Naqvi SMS \& Rashid H (2005). Banana plantlet production through tissue culture. Pak J Bot 36(3): 617-620.

17. Helliot B, Panis B, Poumay Y, Swennen R, Lepoivre P \& Frison E (2002).
Cryopreservation for the elimination of cucumber mosaic and banana streak viruses from banana (Musa spp.). Plant Cell Rep 20(12): 1117-1122.

18. Hwang S, Hwang SC, Molina AB \& Rao VN (2000). Recent developments of Fusarium R and D in Taiwan. Advancing banana and plantain R and D in Asia and the Pacific. Proceeding of the 9th INIBAP-ASPNET. Regional Advisory Committee meeting held at South China Agricultural University, China, $2-5$ November 1999. pp. 84-92.

19. Vuylsteke D (1998). Shoot tip culture for the propagation, conservation and distribution of (Musa spp.) germplasm. Int Insitute of tropical Agriculture, Ibadan, Nigeria. 82.

20. Arinaitwe C, Rubaihayo P \& Magambo M (2000). Proliferation rate effects of cytokinin on banana (Musa spp.) cultivars. Sci Hortic 86: 13-21.

21. Strosse H, Andre E, Sagi L, Swennen R \& Panis B (2008). Adventitious shoot formation is not inherent to micro propagation of banana as it is in maize. Plant Cell, Tissue and Organ Cult 95(3): 321-332.

22. Muhammad A, Hussain I, Naqvi SMS \& Rashid H (2004). Banana plantlet production through tissue culture. Pak $J$ Bot (3): 617-620.

23. Molla MMH, Khanam DM, Khatun MM, AL-Amin \& Malek MA (2004). In vitro Rooting and ex vitro plantlet establishment of BARI banana (Musa spp.) as influenced by different concentration of IBA (Indol-3-buyric Acid). Asian J of Plant Sci 3(2): 196-199. 